\title{
Hybrid Particle Swarm Optimization for Hybrid Flowshop Scheduling Problem with Maintenance Activities
}

\author{
Jun-qing Li, ${ }^{1,2}$ Quan-ke Pan, ${ }^{1}$ and Kun Mao' \\ ${ }^{1}$ State Key Laboratory of Synthetic Automation for Process Industries, Northeastern University, Shenyang 110819, China \\ ${ }^{2}$ College of Computer Science, Liaocheng University, Liaocheng 252059, China \\ Correspondence should be addressed to Jun-qing Li; p2p_jql@126.com
}

Received 21 February 2014; Accepted 30 March 2014; Published 29 April 2014

Academic Editors: P. Agarwal, V. Bhatnagar, and Y. Zhang

Copyright (c) 2014 Jun-qing Li et al. This is an open access article distributed under the Creative Commons Attribution License, which permits unrestricted use, distribution, and reproduction in any medium, provided the original work is properly cited.

\begin{abstract}
A hybrid algorithm which combines particle swarm optimization (PSO) and iterated local search (ILS) is proposed for solving the hybrid flowshop scheduling (HFS) problem with preventive maintenance (PM) activities. In the proposed algorithm, different crossover operators and mutation operators are investigated. In addition, an efficient multiple insert mutation operator is developed for enhancing the searching ability of the algorithm. Furthermore, an ILS-based local search procedure is embedded in the algorithm to improve the exploitation ability of the proposed algorithm. The detailed experimental parameter for the canonical PSO is tuning. The proposed algorithm is tested on the variation of 77 Carlier and Néron's benchmark problems. Detailed comparisons with the present efficient algorithms, including hGA, ILS, PSO, and IG, verify the efficiency and effectiveness of the proposed algorithm.
\end{abstract}

\section{Introduction}

The hybrid flowshop scheduling (HFS) problem has been researched by more and more literatures during last decades. HFS is a typical version of the flowshop scheduling problem (FSP), which has been proved to be an NP-hard problem. Therefore, HFS is also an NP-hard problem and has been researched by more and more heuristics or metaheuristics [111]. In the most present literature about HFS, the common situation is assumed that all machines are available in the production horizon. However, for some critical factors, such as machine random breakdown and preventive maintenance (PM) activity, machines are not available during the whole production horizon. Allaoui and Artiba solved the HFS with maintenance constraints by using an integrating simulation and optimization [12]. Xie and Wang discussed the complexity and algorithms for two-stage flexible flowshop scheduling with availability constraints [13]. Allaoui and Artiba again considered the two-stage HFS with maintenance constraints [14]. Ruiz et al. considered scheduling and preventive maintenance in the flowshop sequencing problem [15].
Naderi et al. applied variable neighborhood structure (VNS) algorithm for solving flexible flow line problems with sequence dependent setup times and different preventive maintenance policies [16]. Berrichi et al. presented a biobjective optimization algorithm for joint production and maintenance scheduling in the parallel machine environments [17]. Luo et al. developed a genetic algorithm for solving two-stage HFS with blocking and machine availability [18]. Allaoui and Artiba investigated Johnson's algorithm for solving optimally or approximately flowshop scheduling problems with unavailability periods [19]. Jabbarizadeh et al. developed a hybrid algorithm for solving the hybrid flexible flowshops with sequence-dependent setup times and machine availability constraints [20]. Besbes et al. tackled hybrid flowshop problem with nonfixed availability constraints [21]. Ma et al. gave a survey of scheduling with deterministic machine availability constraints [22]. Luo et al. solved the HFS with batch-discrete processors and machine maintenance in time windows [23]. Safari and Sadjadi tackled the flowshop scheduling problem with condition-based maintenance constraint and machines breakdown through a hybrid method 
[24]. Wang and Liu solved the two-stage hybrid flowshop scheduling with preventive maintenance using multiobjective tabu search method [25]. Rabiee et al. developed an intelligent hybrid metaheuristic for solving a case of no-wait two-stage flexible flowshop scheduling problem with unrelated parallel machines [26]. Allaoui and Artiba surveyed the maintenance constraints in HFS scheduling problems [27].

In this study, we developed a hybrid algorithm combining particle swarm optimization (PSO) and iterated local search (ILS) algorithms for solving the hybrid flowshop scheduling problems with PM activity. The rest of this paper is organized as follows: Section 2 briefly describes the problem. Next, the related algorithms are presented in Section 3. Section 4 reports the framework of the proposed algorithm. Section 5 illustrates the experimental results and compares them to the present performing algorithms from the literature to demonstrate the superiority of the proposed algorithm. Finally, the last section gives the concluding remarks and future research directions.

\section{Problem Definition}

In this study, we consider a hybrid flowshop scheduling problem in reality production system. The PM activity is considered in the considered HFS problems. Firstly, we give the following assumptions.

(1) Each machine can process only one operation at a time, while each operation can be processed by only one machine at a time.

(2) Preemption is not allowable; that is, each operation must be completed without interruption before its completion.

(3) At each stage, more than one machine from identical parallel machines can be selected for each operation.

(4) The processing time for each operation at each stage is determined.

Under the above assumption, the mathematical model for the problem is given as follows.

\subsection{Variables}

$i$ : job index, $i=1,2, \ldots, n$,

$j$ : stage index, $j=1,2, \ldots, s$,

$k$ : machine index, $k=1,2, \ldots, m$,

$p_{i j}$ : the processing time of job $i$ at stage $j$,

$s_{i, j}$ : the starting time of job $i$ at stage $j$,

$c_{i, j}$ : the completion time of job $i$ at stage $j$,

$\overline{s_{i, j}}$ : the starting time of job $i$ at stage $j$ considering the PM activity,

$\overline{c_{i, j}}$ : the completion time of job $i$ at stage $j$ considering the PM activity,

$P M_{s}^{k}$ : the starting time point of the PM activity on $M_{k}$,
$P M_{e}^{k}$ : the completion time point of the PM activity on $M_{k}$ :

$$
\begin{gathered}
Z_{i j k}= \begin{cases}1, & \begin{array}{l}
\text { if machine } k \text { is selected to process job } i \\
\text { at stage } j
\end{array} \\
0, & \text { otherwise, }\end{cases} \\
Y_{i j k}= \begin{cases}1, & \text { if } s_{i j} \in\left[P M_{s}^{k}, P M_{e}^{k}\right] \wedge Z_{i j k}=1 \\
0, & \text { otherwise. }\end{cases}
\end{gathered}
$$

\subsection{Problem Formula}

$$
f=\min \left\{\max _{1 \leq i \leq n} c_{i, m}\right\}
$$

s.t.

$$
\begin{gathered}
\overline{c_{i, j}} \geq \overline{s_{i, j}}+\overline{p_{i, j}}+Y_{i j k}\left(P M_{e}^{k}-P M_{s}^{k}\right), \\
\overline{s_{i+1, j}} \geq \overline{s_{i, j}}+\overline{p_{i, j}}, \\
\overline{s_{i+1, j+1}} \geq \overline{c_{i, j}}, \\
\sum_{1 \leq k \leq m} Z_{i j k}=1, \quad \forall i, j, \\
Z_{i j k}=\{0,1\} \quad \forall i, j, k, \\
Y_{i j}=\{0,1\} \quad \forall i, j, \\
0 \leq w_{1} \leq 1 .
\end{gathered}
$$

In the mathematical model, the objective is given in formula (2). Constraint (3) guarantees that the PM time should be considered in processing any operation. In Constraint (4), the operation sequence is realized for the same job; that is, the following operation cannot be started until the completion of the predecessor operation of the same job. Constraint (5) shows that, on the same machine, the following operation must wait for the completion of the predecessor operation. Constraint (6) guarantees that each job can select only one available machine at each stage.

\section{The Related Algorithm}

In this study, we consider combining PSO and ILS to construct a hybrid algorithm for solving the HFS with PM activity. The following is to illustrate the literature review of the two related algorithms.

3.1. ILS Algorithm. Iterated local search (ILS), firstly proposed by Stützle [28], is a metaheuristic to increase the ability to jump out of the local optima for the canonical local search methods. It has attracted much attention of researchers for its simplicity, effectiveness, and efficiency, and it has been applied successfully to traveling salesman problem, flowshop scheduling problem, job shop scheduling problem, and vehicle scheduling problem, [28-31] during recent years. The main frame of the canonical ILS is as follows. 
Step 1. Generate an initial solution $x$; let $x^{\prime}=x$ and $x^{*}=x$.

Step 2. Generate a certain number of neighboring solutions around the given solution $x^{\prime}$, find the best neighboring solution $x^{\prime \prime}$, and update the best solution found so far.

Step 3. Let $x=\operatorname{Accept}\left(x^{\prime \prime}, x\right)$.

Step 4. If the stop condition is not satisfied, generated $x^{\prime}=$ perturb $(x)$, go back to Step 2; otherwise, stop the algorithm.

3.2. Particle Swarm Optimization. In 1995, mimicking the flying behavior of a swarm of birds, a novel optimization algorithm named particle swarm optimization (PSO) was developed by Kennedy and Eberhart, which has been verified efficient for solving both continuous and discrete optimization problems [32]. During recent years, many researchers have applied PSO for solving lots of optimization problems [3343].

The flowchart of the canonical PSO is given as follows.

Step 1. Set the system parameters, such as the initial population size, the possibility $\left(p_{l}\right)$ for learning from local best, and the possibility $\left(p_{g}\right)$ for learning from the best solution found so far.

Step 2. Generate the initial population of particles.

Step 3. Store each particle into a vector named local best, where each solution corresponds to the local best of the corresponding particle. Memorize the best solution found so far.

Step 4. For each particle, perform the following steps until the stop condition is satisfied.

Step 5. Randomly generate a number $r_{1}$ between 0 and 1 , if $r_{1}$ is less than $p_{l}$, and then perform the learning process from the local best of the current particle.

Step 6. Randomly generate a number $r_{1}$ between 0 and 1 , if $r_{1}$ is less than $p_{g}$, and then perform the learning process from the global best of the current particle.

Step 7. Record the local best for each particle and the global best found so far.

Step 8. Learn by itself.

Step 9. Go back to Step 4.

\section{Framework of the Proposed Algorithm}

4.1. Solution Representation. For solving the HFS scheduling problems with PM activity, we use the permutation representation mechanism. Give a HFS scheduling problem $n$ jobs, $s$ stages, and $m$ machines; each solution is represented by a vector of integer values, where each integer value represents a job number. Therefore, the length of the solution equals the number of jobs. For example, for a HFS problem with ten jobs

\begin{tabular}{|l|l|l|l|l|l|l|l|l|l|}
$J_{2}$ & $J_{3}$ & $J_{1}$ & $J_{2}$ & $J_{6}$ & $J_{8}$ & $J_{4}$ & $J_{9}$ & $J_{10}$ & $J_{7}$ \\
\hline 2 & 3 & 1 & 5 & 6 & 8 & 4 & 9 & 10 & 7 \\
\hline
\end{tabular}

FIGURE 1: Solution representation.

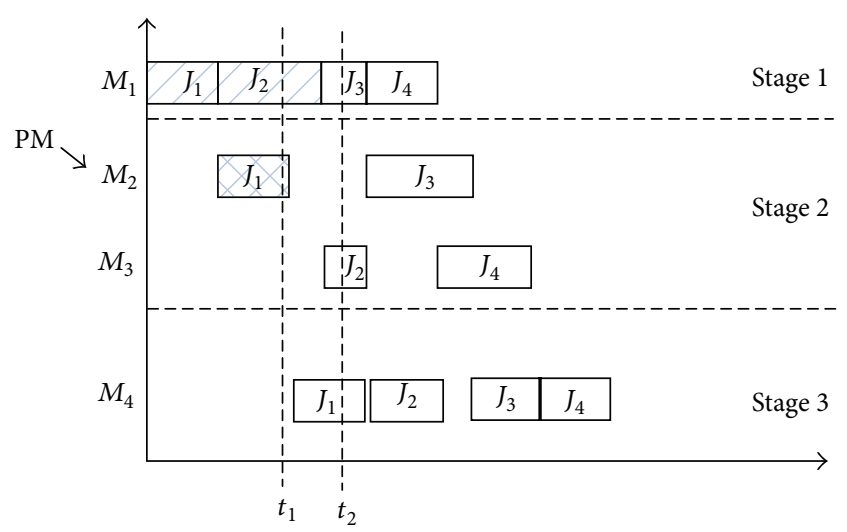

Affected operation

FIGURE 2: Situation 1 of PM activity.

and three stages, Figure 1 gives one solution representation, where the scheduling sequence is $J_{2}, J_{3}, \ldots$, and $J_{7}$.

The sequence in Figure 1 is only for the first stage; that is, at the first stage, each job is scheduled according to the above sequence, while for the following stages, the decoding mechanism is given as follows.

4.2. Decoding without Disruption. It can be seen from the solu-tion representation that the machine selection is not included in the solution representation. The decoding for the above solution representation is given as follows.

Step 1. For the first stage, each job is scheduled according to their sequence in the solution representation. In Figure 1 the first job to be scheduled is $J_{2}$ and the last one is $J_{7}$. Each job selects the first available machine.

Step 2. In the following stages, each job is to be scheduled just after its completion of the previous stage, and select the first available machine from the candidate machines.

4.3. Decoding with PM Activity. When considering the PM activity, that is, at time $t$, there is a PM activity occurring on a given machine $M_{k}$. Then two situations we should consider, that is, the first is that when an operation is just being processed on $M_{k}$ when the disruption event occurs. The second situation is that the affected machine $M_{k}$ is idle and no operation is affected by the PM activity.

(1) Situation 1. For the first situation, an operation is affected by the PM activity. Figure 2 gives the example chart for the situation. From Figure 2, we can see that, at time point $t_{1}$, the machine $M_{2}$ shows a PM activity. It will restart its work at 


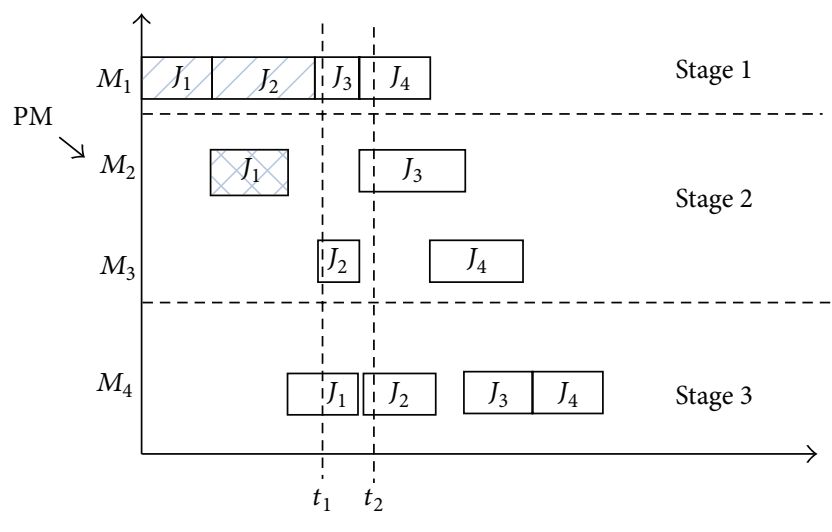

Affected operation

FIGURE 3: Situation 2 of PM activity.

time point $t_{2}$. However, before the PM activity of the machine, the operation $J_{1}$ has started its work and cannot complete its work at time point $t_{1}$. In this situation, we have to do the following works for different realistic production systems.

(i) When an operation is being processed and the processing machine needs to be maintenanced, we have to drop the affected operation and all its following operations. This is appliable for some certain realistic production system, such as steelmaking-casting system. Because of temperature restriction, an operation cannot wait for the restart work of the machine and has to be erased from the system because of its temperature loss. For example, for iron body, when its temperature decreases, its component structure will be destroyed.

(ii) In another situation, the affected operation will keep its previous work and wait for the restart of the affected machine. When the affected machine is available, the affected operation can restart its work and continue the following work.

(2) Situation 2. For the second situation, no working operation is affected by the PM activity. In this situation, we should consider whether there is any operation which is allocated to the affected machine during the PM activity. That is, if an operation is scheduled to be processed on the affected machine before its restart, then we should reconsider the assignment rule, which is given as follows.

(i) If an operation is scheduled to be processed on the affected machine, then the start time of the operation is located between the start and end time point of the PM activity. At that situation, we should assign a new machine for the affected operation if there is another available machine for the affected operation. For example, in Figure 3, the start time of the job $J_{3}$ is between the start and end time of the PM event on $M_{2}$. When the PM event occurs on the machine, we should assign another machine for $J_{3}$; here, we can select $M_{3}$ for processing $J_{3}$. (ii) Another situation is that we cannot select another machine for the affected operation, because of the instability of the system. At that situation, we can only choose to keep the assignment machine for the affected operation and start its work after the availability of the affected machine.

4.4. Initialization Heuristic. In the initialization phase, we presented two heuristics, which are presented as follows.

(1) The First Initial Heuristic. The first initial heuristic is very simple and easy to implement, which is named INT-I with the following steps.

Step 1. Perform the following step for $P_{s}$ times.

Step 2. Randomly generate a particle.

Step 3. Evaluate the new-generated particle and insert it into the current population.

(2) The Second Initial Heuristic. The second initial heuristic is named INT-II, which is given as follows.

Step 1. Generate a particle using the NEH approach [44] and insert it into the initial population.

Step 2. Perform the following step for $P_{s}-1$ times.

Step 3. Randomly generate a particle and evaluate the newgenerated particle.

Step 4. If the new-generated particle is not equal with any individual in the current population, then insert it into the initial population; otherwise, ignore it.

4.5. Discrete PSO Process. Each particle in the current population updates its status through the following three procedures: (1) learning through its history status, (2) learning through its local best, and (3) learning through the global best found so far.

Similar to [34], the discrete version of PSO is realized as follows.

(i) For the process of learning through its history status, we embed the mutation operator in the PSO algorithm. The mutation operators include swap, insert, multiple swap [34], and multiple insert. The multiple insert operator is developed firstly in this study. The detailed steps are as follows. Firstly, randomly produce a position $r_{1}$ range at $\left[2, l_{\mathrm{en}}-1\right], c$, where $l_{\mathrm{en}}$ represents the length of the solution. Secondly, insert the element in the position $\left(r_{1}-1\right)$ to the position at $\left(r_{1}+1\right)$. Thirdly, evaluate the new-generated solution and replace the current solution if a better individual is found.

(ii) For the process of learning through its local best and learning through the global best, apply the crossover operator between the two selected solutions. 
The detailed implementation of the crossover operators is discussed in the following section.

4.6. Crossover Operators. In [45], the authors verified many crossover operators for the regular flowshop (PMX or partially mapped crossover, OP or one point order crossover, TP or two-point order crossover, OX or order crossover, UOB or uniform order based, and several others). The results showed that the offspring generated after crossover tended to be worse than their progenitors on many occasions. In this study, we tested the following crossover operators in HFS with PM environments:

(i) PMX or partially mapped crossover;

(ii) OP or one point order crossover;

(iii) TP or two-point order crossover;

(iv) PTL crossover [34].

4.7. ILS-Based Local Search. To further improve the searching ability of the proposed algorithm, we apply the ILS-based local search for the best solution found so far in each iteration. That is, after the three learning processes discussed in the above section, the ILS-based local search will be applied for the best solution for enhanced searching. The detailed steps of the ILS-based local search are given as follows.

Step 1. For the best solution, perform the following steps until the stop condition is satisfied.

Step 2. Destruction phase: randomly generate aposition in the current solution. Delete the corresponding element from the current solution.

Step 3. Construction phase: for the deleted element, perform the following steps.

Step 3.1. For each candidate position in the current solution, insert the deleted element and evaluate the partial solution.

Step 3.2. Select the best position for the deleted element and insert it into the best position.

4.8. Framework of the Proposed Algorithm. In this study, we proposed a hybrid algorithm for solving the HFS problem with PM activity. In the decoding procedure, we select the following rules to decode each solution; in Situation 1, we choose to keep the work of the affected operation and continue its work after the affected machine is available. In Situation 2, we choose to assign another machine for the affected operation.

The flowchart of the proposed algorithm is given as follows.

Step 1. Set the system parameters.

Step 2. Produce the initial population of particles.

Step 3. Evaluate each particle and record the best solution found so far.
Step 4. If the stop condition is satisfied, stop the algorithm. Otherwise, perform the following steps.

Step 5. Perform learning phase.

Step 5.1. Perform the procedure of learning by itself.

Step 5.2. Perform the procedure of learning through its local best.

Step 5.3. Perform the procedure of learning through the global best.

Step 6. ILS-based local search phase: for the best solution found so far, perform the ILS-based local search procedure.

Step 7. Go back to Step 4.

\section{Numerical Analysis}

The proposed algorithm is coded in $\mathrm{C}++$, on DELL i7 CPU with 16 GB memory. For each instance, we conduct 20 independently runs, and the best, worst, and average values are collected for comparisons.

5.1. Experimental Data. The proposed PSO-ILS algorithm was tested using the variation of the benchmark problems provided by Carlier and Néron [46]. There are 77 instances in Carlier and Néron's benchmark problems, which range from 10 jobs and 5 stages to 15 jobs and 10 stages. Each instance is represented by a three-number file name. The three numbers are number of jobs, number of stages, and problem structure index, which can be referred in [46]. For simplicity, the variations of the 77 benchmark problems are set with the same name. The variation implementation is implemented as follows.

(i) For each instance, run the proposed algorithm without considering any PM activity and get the baseline result.

(ii) In each baseline result, at each stage, randomly select a time point $t$ at which a machine (hereafter called $m_{k}$ ) is working.

(iii) Select the working machine $\left(m_{k}\right)$ and generate a random PM activity duration $d_{b}$.

(iv) Record the PM activity data, including the PM time window $\left[t, t+d_{b}\right]$, and the affected machine $m_{k}$.

5.2. Parameter Tuning for PSO. In the canonical PSO algorithm, the parameters are as follows:

(i) population size: $P_{s}$;

(ii) learning probability from the local best: $c_{1}$;

(iii) learning probability from the global best: $c_{2}$;

(iv) learning probability by itself: $p_{m}$;

(v) crossover operator type;

(vi) mutation operator type. 
TABLE 1: Crossover type.

\begin{tabular}{lc}
\hline Crossover type & Description \\
\hline CT-I & OP \\
CT-II & TP \\
CT-III & PMX \\
CT-IV & SJ2OX \\
CT-V & PTL \\
\hline
\end{tabular}

For each instance, we memorized the best solution found by all the compared algorithms and calculated the relative percentage deviation over the best solution for each compared algorithm, which is computed as follows:

$$
\mathrm{RPD}_{i}=\frac{\text { Comp }_{i}^{k}-\text { Best }_{i}}{\text { Best }_{i}} \times 100,
$$

where $\mathrm{Comp}_{i}^{k}$ is the optimal solution found by the $k$ th compared algorithm, while Best ${ }_{i}$ is the best solution found by all the compared algorithms. In the comparison results, we just calculated the average relative percentage deviation $(\overline{\mathrm{RPD}})$ for each instance.

5.2.1. Crossover Type. To test the impact of different crossover operators, we implemented five kinds of crossover operators, that is, one-point crossover (OP), two-point crossover (TP), partially mapped crossover (PMX), similar job 2-point crossover (SJ2OX), and PTL crossover operator [34]. The description of the given crossover operators is given in Table 1. The comparisons results of different crossover types are given in Table 2. In Table 2, the instance name is given in the first column, while the following five columns report the $\overline{\mathrm{RPD}}$ values for the five compared algorithms. From the results we can see that (1) the algorithm with PTL crossover operator gets better values for 75 out of 77 instances, except for the two instances, that is, Case 13 and Case 22; (2) for solving the given 77 instances with PM activity, in average, the algorithm with PTL crossover operator obtains a relative better result, which is obviously better than the other four compared algorithms. The following algorithms are SJ2OX, TP, PMX, and OP, respectively.

5.2.2. Crossover Probability. The crossover probability for learning from the local best $\left(c_{1}\right)$ and the learning probability from the global best $\left(c_{2}\right)$ are critical for the algorithm. In order to test different learning probabilities, we test five kinds of probabilities, which are given in Table 3. The comparison results for different learning probability are given in Table 4 . It can be seen from Table 4 that CP-I is the best among the five compared algorithms. That is, the two crossover probabilities $c_{1}$ and $c_{2}$ are set to 0.2 and 0.2 , respectively.

5.2.3. Mutation Type. To test the impact of different mutation operators, we implemented four kinds of mutation operators, that is, the swap, insert, multiple swap, and multiple insert operators, which are given in Table 5. Table 6 gives the
TABLE 2: Comparisons of different crossover types.

\begin{tabular}{|c|c|c|c|c|c|}
\hline \multirow{2}{*}{ Case } & \multicolumn{5}{|c|}{$\overline{\mathrm{RPD}}$} \\
\hline & CT-I & CT-II & CT-III & CT-IV & CT-V \\
\hline $\mathrm{j} 10 \mathrm{c} 5 \mathrm{a} 2$ & 0.00 & 0.00 & 0.00 & 0.00 & 0.00 \\
\hline$j 10 c 5 a 3$ & 0.00 & 0.00 & 0.00 & 0.00 & 0.00 \\
\hline j10c5a4 & 0.00 & 0.00 & 0.00 & 0.00 & 0.00 \\
\hline j10c5a5 & 0.00 & 0.00 & 0.00 & 0.00 & 0.00 \\
\hline j10c5a6 & 0.00 & 0.00 & 0.00 & 0.00 & 0.00 \\
\hline j10c5b1 & 0.00 & 0.00 & 0.00 & 0.00 & 0.00 \\
\hline j10c5b2 & 0.00 & 0.00 & 0.00 & 0.00 & 0.00 \\
\hline j10c5b3 & 0.00 & 0.00 & 0.00 & 0.00 & 0.00 \\
\hline j10c5b4 & 0.00 & 0.00 & 0.00 & 0.00 & 0.00 \\
\hline j10c5b5 & 0.00 & 0.00 & 0.00 & 0.00 & 0.00 \\
\hline j10c5b6 & 0.00 & 0.00 & 0.00 & 0.00 & 0.00 \\
\hline $\mathrm{j} 10 \mathrm{c} 5 \mathrm{cl}$ & 0.00 & 0.00 & 0.00 & 0.00 & 0.00 \\
\hline$j 10 c 5 c 2$ & 0.00 & 1.35 & 1.35 & 1.35 & 1.35 \\
\hline$j 10 c 5 c 3$ & 0.00 & 0.00 & 0.00 & 0.00 & 0.00 \\
\hline $\mathrm{j} 10 \mathrm{c} 5 \mathrm{c} 4$ & 1.52 & 0.00 & 0.00 & 0.00 & 0.00 \\
\hline $\mathrm{j} 10 \mathrm{c} 5 \mathrm{c} 5$ & 0.00 & 0.00 & 0.00 & 0.00 & 0.00 \\
\hline$j 10 \mathrm{c} 5 \mathrm{c} 6$ & 0.00 & 0.00 & 0.00 & 0.00 & 0.00 \\
\hline $\mathrm{j} 10 \mathrm{c} 5 \mathrm{~d} 1$ & 0.00 & 0.00 & 0.00 & 0.00 & 0.00 \\
\hline $\mathrm{j} 10 \mathrm{c} 5 \mathrm{~d} 2$ & 0.00 & 0.00 & 0.00 & 0.00 & 0.00 \\
\hline $\mathrm{j} 10 \mathrm{c} 5 \mathrm{~d} 3$ & 0.00 & 0.00 & 0.00 & 0.00 & 0.00 \\
\hline j10c5d4 & 0.00 & 0.00 & 0.00 & 0.00 & 0.00 \\
\hline j10c5d5 & 0.00 & 1.52 & 3.03 & 1.52 & 1.52 \\
\hline j10c5d6 & 0.00 & 0.00 & 0.00 & 0.00 & 0.00 \\
\hline j10c10al & 0.00 & 0.00 & 0.00 & 0.00 & 0.00 \\
\hline $\mathrm{j} 10 \mathrm{c} 10 \mathrm{a} 2$ & 0.00 & 0.00 & 0.00 & 0.00 & 0.00 \\
\hline j10c10a3 & 0.00 & 0.00 & 0.00 & 0.00 & 0.00 \\
\hline j10c10a4 & 0.00 & 0.00 & 0.00 & 0.00 & 0.00 \\
\hline j10c10a5 & 0.00 & 0.00 & 0.00 & 0.00 & 0.00 \\
\hline j10c10a6 & 0.00 & 0.00 & 0.00 & 0.00 & 0.00 \\
\hline j10c10b1 & 0.00 & 0.00 & 0.00 & 0.00 & 0.00 \\
\hline j10c10b2 & 0.00 & 0.00 & 0.00 & 0.00 & 0.00 \\
\hline j10c10b3 & 0.00 & 0.00 & 0.00 & 0.00 & 0.00 \\
\hline j10c10b4 & 0.00 & 0.00 & 0.00 & 0.00 & 0.00 \\
\hline j10c10b5 & 0.00 & 0.00 & 0.00 & 0.00 & 0.00 \\
\hline j10c10b6 & 0.00 & 0.00 & 0.00 & 0.00 & 0.00 \\
\hline j10c10cl & 0.00 & 0.00 & 0.00 & 0.00 & 0.00 \\
\hline $\mathrm{j} 10 \mathrm{c} 10 \mathrm{c} 2$ & 0.00 & 0.00 & 0.00 & 0.00 & 0.00 \\
\hline j10c10c3 & 0.86 & 0.00 & 0.00 & 0.00 & 0.00 \\
\hline $\mathrm{j} 10 \mathrm{c} 10 \mathrm{c} 4$ & 0.00 & 0.00 & 0.00 & 0.00 & 0.00 \\
\hline j10c10c5 & 0.00 & 0.00 & 0.00 & 0.00 & 0.00 \\
\hline j10c10c6 & 0.00 & 0.00 & 0.00 & 0.00 & 0.00 \\
\hline j15c5al & 0.00 & 0.00 & 0.00 & 0.00 & 0.00 \\
\hline$j 15 c 5 a 2$ & 0.00 & 0.00 & 0.00 & 0.00 & 0.00 \\
\hline$j 15 c 5 a 3$ & 0.00 & 0.00 & 0.00 & 0.00 & 0.00 \\
\hline$j 15 c 5 a 4$ & 0.00 & 0.00 & 0.00 & 0.00 & 0.00 \\
\hline j15c5a5 & 0.00 & 0.00 & 0.00 & 0.00 & 0.00 \\
\hline$j 15 c 5 a 6$ & 0.00 & 0.00 & 0.00 & 0.00 & 0.00 \\
\hline j15c5b1 & 0.00 & 0.00 & 0.00 & 0.00 & 0.00 \\
\hline$j 15 c 5 b 2$ & 0.00 & 0.00 & 0.00 & 0.00 & 0.00 \\
\hline$j 15 c 5 b 3$ & 0.00 & 0.00 & 0.00 & 0.00 & 0.00 \\
\hline
\end{tabular}


TABLE 2: Continued.

\begin{tabular}{lccccc}
\hline Case & & & $\overline{\text { RPD }}$ & \\
\hline j15c5b4 & 0.00 & 0.00 & 0.00 & 0.00 & 0.00 \\
j15c5b5 & 0.00 & 0.00 & 0.00 & 0.00 & 0.00 \\
j15c5b6 & 0.00 & 0.00 & 0.00 & 0.00 & 0.00 \\
j15c5c1 & 1.18 & 1.18 & 0.00 & 1.18 & 0.00 \\
j15c5c2 & 0.00 & 0.00 & 0.00 & 0.00 & 0.00 \\
j15c5c3 & 1.15 & 0.00 & 1.15 & 0.00 & 0.00 \\
j15c5c4 & 1.12 & 1.12 & 1.12 & 1.12 & 0.00 \\
j15c5c5 & 2.67 & 0.00 & 0.00 & 0.00 & 0.00 \\
j15c5c6 & 0.00 & 0.00 & 0.00 & 0.00 & 0.00 \\
j15c5d1 & 0.00 & 0.00 & 0.00 & 0.00 & 0.00 \\
j15c5d2 & 1.18 & 0.00 & 0.00 & 0.00 & 0.00 \\
j15c5d3 & 0.00 & 0.00 & 0.00 & 0.00 & 0.00 \\
j15c5d4 & 2.38 & 1.19 & 1.19 & 1.19 & 0.00 \\
j15c5d5 & 0.00 & 1.25 & 1.25 & 0.00 & 0.00 \\
j15c5d6 & 1.23 & 1.23 & 0.00 & 1.23 & 0.00 \\
j15c10a1 & 0.00 & 0.00 & 0.00 & 0.00 & 0.00 \\
j15c10a2 & 0.00 & 0.00 & 0.00 & 0.00 & 0.00 \\
j15c10a3 & 0.00 & 0.00 & 0.00 & 0.00 & 0.00 \\
j15c10a4 & 0.00 & 0.00 & 0.00 & 0.00 & 0.00 \\
j15c10a5 & 0.00 & 0.00 & 0.00 & 0.00 & 0.00 \\
j15c10a6 & 0.00 & 0.00 & 0.00 & 0.00 & 0.00 \\
j15c10b1 & 0.00 & 0.00 & 0.00 & 0.00 & 0.00 \\
j15c10b2 & 0.00 & 0.00 & 0.00 & 0.00 & 0.00 \\
j15c10b3 & 0.00 & 0.00 & 0.00 & 0.00 & 0.00 \\
j15c10b4 & 0.00 & 0.00 & 0.00 & 0.00 & 0.00 \\
j15c10b5 & 0.00 & 0.00 & 0.00 & 0.00 & 0.00 \\
j15c10b6 & 0.00 & 0.00 & 0.00 & 0.00 & 0.00 \\
\hline Average & 0.17 & 0.11 & 0.12 & 0.10 & 0.04 \\
\hline & & & & & \\
& & CT-II & \\
\hline
\end{tabular}

TABLE 3: Crossover probability.

\begin{tabular}{lcc}
\hline Crossover probability & $c_{1}$ & $c_{2}$ \\
\hline CP-I & 0.2 & 0.2 \\
CP-II & 0.2 & 0.8 \\
CP-III & 0.5 & 0.5 \\
CP-IV & 0.8 & 0.2 \\
CP-V & 0.8 & 0.8 \\
\hline
\end{tabular}

TABLE 4: Comparisons of different crossover probabilities.

\begin{tabular}{lccccc}
\hline Case & CP-I & CP-II & $\begin{array}{r}\overline{\mathrm{RPD}} \\
\text { CP-III }\end{array}$ & CP-IV & CP-V \\
\hline Average & $\mathbf{0 . 0 8}$ & 0.20 & 0.15 & 0.13 & 0.11 \\
\hline
\end{tabular}

comparison results of different mutation types. It can be seen from Table 6 that the proposed multiple insert mutation operator performs the best among the compared algorithms.
TABLE 5: Mutation probability.

\begin{tabular}{lc}
\hline Mutation type & Description \\
\hline MT-I & Swap \\
MT-II & Insert \\
MT-III & Multiple swap \\
MT-IV & Multiple insert \\
\hline
\end{tabular}

TABLE 6: Comparisons of different mutation types.

\begin{tabular}{lcccc}
\hline \multirow{2}{*}{ Case } & \multicolumn{4}{c}{$\overline{\overline{R P D}}$} \\
& MT-I & MT-II & MT-IIII & MT-IV \\
\hline Average & 0.08 & 0.08 & 0.02 & $\mathbf{0 . 0 1}$ \\
\hline
\end{tabular}

TABLE 7: Mutation probability.

\begin{tabular}{lc}
\hline Mutation probability & $p_{m}$ \\
\hline MP-I & 0.1 \\
MP-II & 0.2 \\
MP-III & 0.5 \\
MP-IV & 0.8 \\
MP-V & 0.9 \\
\hline
\end{tabular}

TABLE 8: Comparisons of different mutation types.

\begin{tabular}{lccccc}
\hline Case & MP-I & MP-II & $\begin{array}{r}\overline{\mathrm{RPD}} \\
\text { MP-III }\end{array}$ & MP-IV & MP-V \\
\hline Average & 0.12 & 0.09 & 0.06 & 0.08 & $\mathbf{0 . 0 2}$
\end{tabular}

TABle 9: Population size.

\begin{tabular}{lc}
\hline Population size & $p_{s}$ \\
\hline PS-I & 10 \\
PS-II & 20 \\
PS-III & 30 \\
PS-IV & 50 \\
PS-V & 100
\end{tabular}

TABLE 10: Comparisons of different population sizes.

\begin{tabular}{|c|c|c|c|c|c|}
\hline \multirow{2}{*}{ Case } & \multicolumn{5}{|c|}{$\overline{\mathrm{RPD}}$} \\
\hline & PS-I & PS-II & PS-III & PS-IV & PS-V \\
\hline Average & 0.06 & 0.08 & 0.03 & 0.06 & 0.00 \\
\hline
\end{tabular}

TABLE 11: Different parameters for the canonical PSO.

\begin{tabular}{lccc}
\hline & Parameter & Value & Description \\
\hline 1 & Crossover type & CT-V & PTL \\
2 & Crossover probability & CP-I & $c_{1}=0.2, c_{2}=0.2$ \\
3 & Mutation type & MT-IV & Multiple insert \\
4 & Mutation probability & MP-V & 0.9 \\
5 & Population size & PS-V & 100 \\
\hline
\end{tabular}

5.2.4. Mutation Probability. To test the impact of different mutation probabilities, we implemented five kinds of mutation probabilities, that is, $0.1,0.2,0.5,0.8$, and 0.9 , which 
TABLE 12: Comparisons of the best $\overline{\mathrm{RPD}}$ values.

\begin{tabular}{|c|c|c|c|c|c|}
\hline \multirow{2}{*}{ Case } & \multicolumn{5}{|c|}{$\overline{\mathrm{RPD}}$} \\
\hline & PSO-ILS & ILS & IG & PSO & hGA \\
\hline j10c5a2 & 0.00 & 0.00 & 0.00 & 0.00 & 0.00 \\
\hline j10c5a3 & 0.00 & 0.00 & 0.00 & 0.00 & 0.00 \\
\hline j10c5a4 & 0.00 & 0.00 & 0.00 & 0.00 & 0.00 \\
\hline j10c5a5 & 0.00 & 0.00 & 0.00 & 0.00 & 0.00 \\
\hline j10c5a6 & 0.00 & 0.00 & 0.00 & 0.00 & 0.00 \\
\hline j10c5b1 & 0.00 & 0.00 & 0.00 & 0.00 & 0.00 \\
\hline j10c5b2 & 0.00 & 0.00 & 0.00 & 0.00 & 0.00 \\
\hline j10c5b3 & 0.00 & 0.00 & 0.00 & 0.00 & 0.00 \\
\hline j10c5b4 & 0.00 & 0.00 & 1.64 & 0.00 & 0.00 \\
\hline j10c5b5 & 0.00 & 0.00 & 0.00 & 0.00 & 0.00 \\
\hline j10c5b6 & 0.00 & 0.00 & 0.00 & 0.00 & 0.00 \\
\hline j10c5cl & 0.00 & 7.35 & 5.88 & 0.00 & 0.00 \\
\hline$j 10 c 5 c 2$ & 0.00 & 2.70 & 2.70 & 0.00 & 0.00 \\
\hline$j 10 \mathrm{c} 5 \mathrm{c} 3$ & 0.00 & 4.17 & 2.78 & 0.00 & 0.00 \\
\hline j10c5c4 & 0.00 & 4.55 & 4.55 & 0.00 & 0.00 \\
\hline $\mathrm{j} 10 \mathrm{c} 5 \mathrm{c} 5$ & 0.00 & 5.13 & 1.28 & 0.00 & 0.00 \\
\hline j10c5c6 & 0.00 & 4.35 & 1.45 & 0.00 & 0.00 \\
\hline j10c5d1 & 0.00 & 4.55 & 1.52 & 0.00 & 0.00 \\
\hline j10c5d2 & 0.00 & 1.35 & 0.00 & 0.00 & 0.00 \\
\hline j10c5d3 & 0.00 & 3.13 & 1.56 & 0.00 & 0.00 \\
\hline j10c5d4 & 0.00 & 2.86 & 2.86 & 0.00 & 0.00 \\
\hline j10c5d5 & 0.00 & 4.55 & 4.55 & 1.52 & 1.52 \\
\hline j10c5d6 & 0.00 & 4.84 & 3.23 & 0.00 & 0.00 \\
\hline j10c10a1 & 0.00 & 0.00 & 0.00 & 0.00 & 0.00 \\
\hline j10c10a2 & 0.00 & 2.53 & 3.16 & 0.00 & 0.00 \\
\hline j10c10a3 & 0.00 & 1.35 & 0.00 & 0.00 & 0.00 \\
\hline j10c10a4 & 0.00 & 0.00 & 0.00 & 0.00 & 0.00 \\
\hline j10c10a5 & 0.00 & 0.00 & 0.00 & 0.00 & 0.00 \\
\hline j10c10a6 & 0.00 & 2.05 & 4.11 & 0.00 & 0.00 \\
\hline j10c10b1 & 0.00 & 0.00 & 0.00 & 0.00 & 0.00 \\
\hline j10c10b2 & 0.00 & 0.64 & 0.64 & 0.00 & 0.00 \\
\hline j10c10b3 & 0.00 & 0.00 & 0.00 & 0.00 & 0.00 \\
\hline j10c10b4 & 0.00 & 0.00 & 0.00 & 0.00 & 0.00 \\
\hline j10c10b5 & 0.00 & 0.00 & 0.00 & 0.00 & 0.00 \\
\hline j10c10b6 & 0.00 & 0.00 & 0.00 & 0.00 & 0.00 \\
\hline j10c10c1 & 0.00 & 2.61 & 1.74 & 0.00 & 0.00 \\
\hline $\mathrm{j} 10 \mathrm{c} 10 \mathrm{c} 2$ & 0.00 & 2.52 & 1.68 & 0.00 & 0.00 \\
\hline j10c10c3 & 0.00 & 3.45 & 2.59 & 0.00 & 0.00 \\
\hline j10c10c4 & 0.00 & 2.50 & 1.67 & 0.00 & 0.00 \\
\hline j10c10c5 & 0.00 & 1.59 & 3.17 & 0.00 & 0.00 \\
\hline j10c10c6 & 0.00 & 1.89 & 3.77 & 0.00 & 0.00 \\
\hline j15c5al & 0.00 & 0.00 & 0.00 & 0.00 & 0.00 \\
\hline j15c5a2 & 0.00 & 0.00 & 0.00 & 0.00 & 0.00 \\
\hline j15c5a3 & 0.00 & 0.00 & 0.00 & 0.00 & 0.00 \\
\hline j15c5a4 & 0.00 & 0.00 & 0.00 & 0.00 & 0.00 \\
\hline j15c5a5 & 0.00 & 0.00 & 0.00 & 0.00 & 0.00 \\
\hline j15c5a6 & 0.00 & 0.00 & 0.00 & 0.00 & 0.00 \\
\hline j15c5b1 & 0.00 & 0.00 & 0.00 & 0.00 & 0.00 \\
\hline j15c5b2 & 0.00 & 0.00 & 0.00 & 0.00 & 0.00 \\
\hline j15c5b3 & 0.00 & 0.00 & 0.00 & 0.00 & 0.00 \\
\hline
\end{tabular}

TABLE 12: Continued.

\begin{tabular}{|c|c|c|c|c|c|}
\hline \multirow{2}{*}{ Case } & \multicolumn{5}{|c|}{$\overline{\mathrm{RPD}}$} \\
\hline & PSO-ILS & ILS & IG & PSO & hGA \\
\hline $\mathrm{j} 15 \mathrm{c} 5 \mathrm{~b} 4$ & 0.00 & 0.00 & 0.00 & 0.00 & 0.00 \\
\hline j15c5b5 & 0.00 & 0.60 & 0.00 & 0.00 & 0.00 \\
\hline j15c5b6 & 0.00 & 0.00 & 0.00 & 0.00 & 0.00 \\
\hline $\mathrm{j} 15 \mathrm{c} 5 \mathrm{cl}$ & 0.00 & 5.88 & 8.24 & 0.00 & 1.18 \\
\hline$j 15 c 5 c 2$ & 0.00 & 4.40 & 4.40 & 0.00 & 0.00 \\
\hline$j 15 c 5 c 3$ & 0.00 & 10.34 & 8.05 & 0.00 & 0.00 \\
\hline$j 15 c 5 c 4$ & 0.00 & 3.37 & 5.62 & 0.00 & 0.00 \\
\hline$j 15 c 5 c 5$ & 0.00 & 9.46 & 10.81 & 0.00 & 1.35 \\
\hline$j 15 c 5 c 6$ & 0.00 & 7.69 & 6.59 & 0.00 & 0.00 \\
\hline j15c5d1 & 0.00 & 0.00 & 0.00 & 0.00 & 0.00 \\
\hline $\mathrm{j} 15 \mathrm{c} 5 \mathrm{~d} 2$ & 0.00 & 9.52 & 9.52 & 1.19 & 0.00 \\
\hline$j 15 c 5 d 3$ & 0.00 & 7.23 & 6.02 & 0.00 & 0.00 \\
\hline j15c5d4 & 0.00 & 7.14 & 5.95 & 1.19 & 1.19 \\
\hline $\mathrm{j} 15 \mathrm{c} 5 \mathrm{~d} 5$ & 0.00 & 8.86 & 8.86 & 1.27 & 0.00 \\
\hline j15c5d6 & 0.00 & 4.94 & 4.94 & 1.23 & 1.23 \\
\hline j15c10al & 0.00 & 0.00 & 0.00 & 0.00 & 0.00 \\
\hline j15c10a2 & 0.00 & 2.00 & 2.00 & 0.00 & 0.00 \\
\hline j15c10a3 & 0.00 & 0.00 & 1.01 & 0.00 & 0.00 \\
\hline j15c10a4 & 0.00 & 0.00 & 1.78 & 0.00 & 0.00 \\
\hline j15c10a5 & 0.00 & 0.55 & 0.00 & 0.00 & 0.00 \\
\hline j15c10a6 & 0.00 & 1.00 & 0.00 & 0.00 & 0.00 \\
\hline j15c10b1 & 0.00 & 0.00 & 0.00 & 0.00 & 0.00 \\
\hline j15c10b2 & 0.00 & 0.00 & 0.00 & 0.00 & 0.00 \\
\hline j15c10b3 & 0.00 & 0.00 & 0.00 & 0.00 & 0.00 \\
\hline j15c10b4 & 0.00 & 0.00 & 0.00 & 0.00 & 0.00 \\
\hline j15c10b5 & 0.00 & 0.00 & 0.00 & 0.00 & 0.00 \\
\hline j15c10b6 & 0.00 & 0.00 & 0.00 & 0.00 & 0.00 \\
\hline Average & 0.00 & 2.00 & 1.82 & 0.08 & 0.08 \\
\hline
\end{tabular}

are given in Table 7. Table 8 gives the comparison results of different mutation probabilities. It can be seen from Table 8 that mutation probability with the value 0.9 performs the best among the compared algorithms.

5.2.5. Population Size. To test the impact of different population sizes, we implemented five kinds of population sizes, that is, $10,20,30,50$, and 100, which are given in Table 9. Table 10 gives the comparison results of different population sizes. It can be seen from Table 10 that population size with the value 100 performs the best among the compared algorithms.

5.2.6. The Final Parameters. After the comparison results for each kind of parameter, we can conclude the best parameters for the canonical PSO algorithm, which are given in Table 11.

5.3. Comparisons Analysis. To make a pair comparison with the present efficient algorithms, we coded the following algorithms to solve the HFS problem with PM activity. These compared algorithms include hGA by Ruiz and Maroto [47], IG by Ruiz and Stützle [48], ILS by Dong et al. [31], and PSO 
TABLE 13: Comparisons of average $\overline{\mathrm{RPD}}$ values.

\begin{tabular}{|c|c|c|c|c|c|}
\hline \multirow{2}{*}{ Case } & \multicolumn{5}{|c|}{$\overline{\overline{\mathrm{RPD}}}$} \\
\hline & PSO-ILS & ILS & IG & PSO & hGA \\
\hline j10c5a2 & 0.00 & 0.00 & 0.00 & 0.00 & 0.00 \\
\hline j10c5a3 & 0.00 & 0.00 & 0.00 & 0.00 & 0.00 \\
\hline j10c5a4 & 0.00 & 0.00 & 0.00 & 0.00 & 0.00 \\
\hline j10c5a5 & 0.00 & 0.00 & 0.00 & 0.00 & 0.00 \\
\hline j10c5a6 & 0.00 & 0.73 & 1.45 & 0.00 & 0.00 \\
\hline j10c5b1 & 0.00 & 0.00 & 0.00 & 0.00 & 0.00 \\
\hline $\mathrm{j} 10 \mathrm{c} 5 \mathrm{~b} 2$ & 0.00 & 0.00 & 0.00 & 0.00 & 0.00 \\
\hline j10c5b3 & 0.00 & 0.55 & 0.00 & 0.00 & 0.00 \\
\hline j10c5b4 & 0.00 & 0.49 & 3.44 & 0.00 & 0.00 \\
\hline j10c5b5 & 0.00 & 0.00 & 0.00 & 0.00 & 0.00 \\
\hline j10c5b6 & 0.00 & 0.00 & 0.00 & 0.00 & 0.00 \\
\hline j10c5cl & 0.29 & 8.82 & 8.53 & 0.00 & 0.00 \\
\hline$j 10 \mathrm{c} 5 \mathrm{c} 2$ & 0.81 & 3.50 & 3.77 & 0.00 & 0.00 \\
\hline$j 10 c 5 c 3$ & 0.00 & 5.83 & 4.17 & 0.00 & 0.00 \\
\hline $\mathrm{j} 10 \mathrm{c} 5 \mathrm{c} 4$ & 0.00 & 6.36 & 6.06 & 0.00 & 0.00 \\
\hline j10c5c5 & 0.00 & 6.41 & 3.59 & 0.00 & 0.00 \\
\hline j10c5c6 & 0.00 & 5.80 & 4.93 & 0.00 & 0.00 \\
\hline j10c5d1 & 0.00 & 5.15 & 4.85 & 0.00 & 0.00 \\
\hline $\mathrm{j} 10 \mathrm{c} 5 \mathrm{~d} 2$ & 0.00 & 2.97 & 2.70 & 0.00 & 0.00 \\
\hline j10c5d3 & 0.00 & 6.25 & 5.94 & 0.00 & 0.00 \\
\hline $\mathrm{j} 10 \mathrm{c} 5 \mathrm{~d} 4$ & 0.00 & 3.71 & 4.57 & 0.00 & 0.00 \\
\hline j10c5d5 & 0.00 & 5.11 & 5.11 & 0.60 & 0.60 \\
\hline j10c5d6 & 0.00 & 6.45 & 5.81 & 0.00 & 0.00 \\
\hline j10c10al & 0.00 & 0.00 & 0.00 & 0.00 & 0.00 \\
\hline j10c10a2 & 0.00 & 3.67 & 3.67 & 0.00 & 0.00 \\
\hline j10c10a3 & 0.00 & 2.03 & 0.68 & 0.00 & 0.00 \\
\hline j10c10a4 & 0.00 & 0.00 & 1.48 & 0.00 & 0.00 \\
\hline j10c10a5 & 0.00 & 0.00 & 3.24 & 0.00 & 0.00 \\
\hline j10c10a6 & 0.00 & 3.70 & 4.79 & 0.00 & 0.00 \\
\hline j10c10b1 & 0.00 & 0.00 & 0.00 & 0.00 & 0.00 \\
\hline j10c10b2 & 0.00 & 0.89 & 2.80 & 0.00 & 0.00 \\
\hline j10c10b3 & 0.00 & 0.12 & 0.00 & 0.00 & 0.00 \\
\hline j10c10b4 & 0.00 & 0.00 & 0.00 & 0.00 & 0.00 \\
\hline j10c10b5 & 0.00 & 0.00 & 0.12 & 0.00 & 0.00 \\
\hline j10c10b6 & 0.00 & 0.36 & 0.36 & 0.00 & 0.00 \\
\hline j10c10c1 & 0.00 & 3.83 & 3.48 & 0.00 & 0.00 \\
\hline $\mathrm{j} 10 \mathrm{c} 10 \mathrm{c} 2$ & 0.00 & 3.53 & 2.69 & 0.00 & 0.00 \\
\hline j10c10c3 & 0.00 & 3.61 & 3.09 & 0.17 & 0.34 \\
\hline $\mathrm{j} 10 \mathrm{c} 10 \mathrm{c} 4$ & 0.00 & 3.17 & 2.83 & 0.00 & 0.00 \\
\hline j10c10c5 & 0.00 & 4.92 & 5.71 & 0.00 & 0.00 \\
\hline j10c10c6 & 0.00 & 2.45 & 4.53 & 0.00 & 0.00 \\
\hline j15c5al & 0.00 & 0.79 & 0.56 & 0.00 & 0.00 \\
\hline $\mathrm{j} 15 \mathrm{c} 5 \mathrm{a} 2$ & 0.00 & 0.00 & 0.00 & 0.00 & 0.00 \\
\hline j15c5a3 & 0.00 & 0.00 & 0.00 & 0.00 & 0.00 \\
\hline $\mathrm{j} 15 \mathrm{c} 5 \mathrm{a} 4$ & 0.00 & 0.00 & 0.26 & 0.00 & 0.00 \\
\hline j15c5a5 & 0.00 & 0.00 & 0.49 & 0.00 & 0.00 \\
\hline j15c5a6 & 0.00 & 0.00 & 0.00 & 0.00 & 0.00 \\
\hline j15c5b1 & 0.00 & 0.00 & 0.00 & 0.00 & 0.00 \\
\hline$j 15 c 5 b 2$ & 0.00 & 0.00 & 0.00 & 0.00 & 0.00 \\
\hline$j 15 c 5 b 3$ & 0.00 & 0.00 & 0.13 & 0.00 & 0.00 \\
\hline
\end{tabular}

TABLE 13: Continued.

\begin{tabular}{|c|c|c|c|c|c|}
\hline \multirow{2}{*}{ Case } & \multicolumn{5}{|c|}{$\overline{\mathrm{RPD}}$} \\
\hline & PSO-ILS & ILS & IG & PSO & hGA \\
\hline $\mathrm{j} 15 \mathrm{c} 5 \mathrm{~b} 4$ & 0.00 & 0.54 & 0.68 & 0.00 & 0.00 \\
\hline j15c5b5 & 0.00 & 1.93 & 1.08 & 0.00 & 0.00 \\
\hline j15c5b6 & 0.00 & 0.00 & 0.11 & 0.00 & 0.00 \\
\hline $\mathrm{j} 15 \mathrm{c} 5 \mathrm{cl}$ & 0.00 & 7.71 & 8.88 & 0.23 & 0.47 \\
\hline$j 15 c 5 c 2$ & 0.00 & 6.81 & 6.59 & 0.22 & 0.00 \\
\hline$j 15 c 5 c 3$ & 0.00 & 11.72 & 10.11 & 0.23 & 0.23 \\
\hline$j 15 c 5 c 4$ & 0.00 & 5.58 & 5.80 & 0.22 & 0.00 \\
\hline$j 15 c 5 c 5$ & 0.00 & 10.46 & 12.06 & 0.80 & 1.88 \\
\hline$j 15 c 5 c 6$ & 0.00 & 9.45 & 9.01 & 0.00 & 0.00 \\
\hline $\mathrm{j} 15 \mathrm{c} 5 \mathrm{~d} 1$ & 0.00 & 0.00 & 0.00 & 0.00 & 0.00 \\
\hline $\mathrm{j} 15 \mathrm{c} 5 \mathrm{~d} 2$ & 0.00 & 9.48 & 9.48 & 0.95 & 0.47 \\
\hline$j 15 c 5 d 3$ & 0.00 & 7.93 & 7.45 & 0.24 & 0.00 \\
\hline $\mathrm{j} 15 \mathrm{c} 5 \mathrm{~d} 4$ & 0.00 & 7.58 & 7.58 & 0.71 & 0.71 \\
\hline j15c5d5 & 0.25 & 10.53 & 10.53 & 0.25 & 0.00 \\
\hline j15c5d6 & 0.00 & 6.14 & 6.39 & 0.74 & 0.74 \\
\hline j15c10al & 0.00 & 0.17 & 0.00 & 0.00 & 0.00 \\
\hline $\mathrm{j} 15 \mathrm{c} 10 \mathrm{a} 2$ & 0.00 & 3.30 & 3.20 & 0.00 & 0.00 \\
\hline j15c10a3 & 0.00 & 0.61 & 2.32 & 0.00 & 0.00 \\
\hline j15c10a4 & 0.00 & 0.00 & 1.96 & 0.00 & 0.00 \\
\hline j15c10a5 & 0.00 & 0.77 & 0.77 & 0.00 & 0.00 \\
\hline j15c10a6 & 0.00 & 2.70 & 0.10 & 0.00 & 0.00 \\
\hline j15c10b1 & 0.00 & 0.00 & 0.00 & 0.00 & 0.00 \\
\hline j15c10b2 & 0.00 & 0.00 & 0.21 & 0.00 & 0.00 \\
\hline j15c10b3 & 0.00 & 0.00 & 0.00 & 0.00 & 0.00 \\
\hline j15c10b4 & 0.00 & 0.00 & 0.00 & 0.00 & 0.00 \\
\hline j15c10b5 & 0.00 & 0.60 & 0.20 & 0.00 & 0.00 \\
\hline j15c10b6 & 0.00 & 0.00 & 0.00 & 0.00 & 0.00 \\
\hline Average & 0.02 & 2.67 & 2.73 & 0.07 & 0.07 \\
\hline
\end{tabular}

by Liao et al. [49]. The parameters for the compared algorithms are set to the same values in their literature, except that the stop condition is set to 20 seconds.

The comparison results for the best $\overline{\mathrm{RPD}}$ values are given in Table 12. It can be seen from Table 12 that (1) for solving the HFS with PM activities, the proposed algorithm obtains all optimal results for 77 benchmark instances, which is obviously better than the other compared algorithms; (2) in average, the proposed algorithm is also better than the other compared algorithms; (3) the proposed PSO-ILS algorithm is better than the canonical PSO algorithm, which also verifies the efficiency of the ILS-based local search; (4) the proposed algorithm is better than the canonical IG algorithm, which shows the exploration ability of the proposed algorithm.

Table 13 reports the comparison results for the average $\overline{\mathrm{RPD}}$ values. It can be seen from Table 13 that (1) the proposed algorithm obtains 74 optimal values out of 77 instances; (2) in average, the PSO-ILS algorithm obtains the best average $\overline{\mathrm{RPD}}$ values, which is obviously better than the other algorithms. The following algorithms are PSO, hGA, ILS, and IG, respectively. 


\section{Conclusions}

In this study, we proposed a hybrid algorithm for solving the HFS with PM activities. In the proposed algorithms, different crossover and mutation operators are applied for the learning procedure. The ILS-based local search procedure is embedded in the proposed algorithm to further improve the searching ability of the algorithm. Variation versions of 77 Carlier and Néron's benchmark problems are presented to adapt to the realistic industrial horizon. Experimental comparisons with four present algorithms show the efficiency and effectiveness of the proposed algorithm. The future work is to apply the proposed algorithm for solving rescheduling problems in hybrid and flexible environments [50-52].

\section{Conflict of Interests}

The authors declare that there is no conflict of interests regarding the publication of this paper.

\section{Acknowledgments}

This research is partially supported by the National Science Foundation of China under Grant nos. 61104179 and 61174187, the Basic Scientific Research Foundation of Northeastern University under Grant no. N110208001, the Starting Foundation of Northeastern University under Grant no. 29321006, the Science Foundation of Liaoning Province in China (2013020016), and the Science Research and Development of Provincial Department of Public Education of Shandong under Grant no. J12LN39.

\section{References}

[1] A. Costa, F. A. Cappadonna, and S. Fichera, "A dual encodingbased meta-heuristic algorithm for solving a constrained hybrid flow shop scheduling problem," Computers and Industrial Engineering, vol. 64, no. 4, pp. 937-958, 2013.

[2] E. Figielska, "A heuristic for scheduling in a two-stage hybrid flowshop with renewable resources shared among the stages," European Journal of Operational Research, vol. 236, no. 2, pp. 433-444, 201.

[3] K. Mao, Q. K. Pan, X. Pang, and T. Chai, "A novel Lagrangian relaxation approach for a hybrid flowshop scheduling problem in the steelmaking-continuous casting process," European Journal of Operational Research, vol. 236, no. 1, pp. 51-60, 2014.

[4] H. Luo, A. Zhang, and G. Q. Huang, "Active scheduling for hybrid flowshop with family setup time and inconsistent family formation," Journal of Intelligent Manufacturing, 2013.

[5] L. C. Wang, Y. Y. Chen, T. L. Chen, C. Y. Cheng, and C. W. Chang, "A hybrid flowshop scheduling model considering dedicated machines and lot-splitting for the solar cell industry," International Journal of Systems Science, 2013.

[6] T. P. Chung and C. J. Liao, "An immunoglobulin-based artificial immune system for solving the hybrid flow shop problem," Applied Soft Computing, vol. 13, no. 8, pp. 3729-3736, 2013.

[7] M. Abbas Bozorgirad and R. Logendran, "Bi-criteria group scheduling in hybrid flowshops," International Journal of Production Economics, vol. 145, no. 2, pp. 599-612, 2013.
[8] F. D. Chou, "Particle swarm optimization with cocktail decoding method for hybrid flow shop scheduling problems with multiprocessor tasks," International Journal of Production Economics, vol. 141, no. 1, pp. 137-145, 2013.

[9] J. Yang, "A two-stage hybrid flow shop with dedicated machines at the first stage," Computers and Operations Research, vol. 40, no. 12, pp. 2836-2843, 2013.

[10] P. Ramezani, M. Rabiee, and F. Jolai, "No-wait flexible flowshop with uniform parallel machines and sequence-dependent setup time: a hybrid meta-heuristic approach," Journal of Intelligent Manufacturing.

[11] T. H. Tran and K. M. Ng, "A hybrid water flow algorithm for multi-objective flexible flow shop scheduling problems," Engineering Optimization, vol. 45, no. 4, pp. 483-502, 2013.

[12] H. Allaoui and A. Artiba, "Integrating simulation and optimization to schedule a hybrid flow shop with maintenance constraints," Computers and Industrial Engineering, vol. 47, no. 4, pp. 431-450, 2004.

[13] J. Xie and X. Wang, "Complexity and algorithms for twostage flexible flowshop scheduling with availability constraints," Computers and Mathematics with Applications, vol. 50, no. 1012, pp. 1629-1638, 2005.

[14] H. Allaoui and A. Artiba, "Scheduling two-stage hybrid flow shop with availability constraints," Computers and Operations Research, vol. 33, no. 5, pp. 1399-1419, 2006.

[15] R. Ruiz, J. Carlos García-Díaz, and C. Maroto, "Considering scheduling and preventive maintenance in the flowshop sequencing problem," Computers and Operations Research, vol. 34, no. 11, pp. 3314-3330, 2007.

[16] B. Naderi, M. Zandieh, and S. M. T. Fatemi Ghomi, "A study on integrating sequence dependent setup time flexible flow lines and preventive maintenance scheduling," Journal of Intelligent Manufacturing, vol. 20, no. 6, pp. 683-694, 2009.

[17] A. Berrichi, L. Amodeo, F. Yalaoui, E. Châtelet, and M. Mezghiche, "Bi-objective optimization algorithms for joint production and maintenance scheduling: application to the parallel machine problem," Journal of Intelligent Manufacturing, vol. 20, no. 4, pp. 389-400, 2009.

[18] H. Luo, G. Q. Huang, Y. Zhang, Q. Dai, and X. Chen, “Twostage hybrid batching flowshop scheduling with blocking and machine availability constraints using genetic algorithm," Robotics and Computer-Integrated Manufacturing, vol. 25, no. 6, pp. 962-971, 2009.

[19] H. Allaoui and A. Artiba, "Johnson's algorithm: a key to solve optimally or approximately flow shop scheduling problems with unavailability periods," International Journal of Production Economics, vol. 121, no. 1, pp. 81-87, 2009.

[20] F. Jabbarizadeh, M. Zandieh, and D. Talebi, "Hybrid flexible flowshops with sequence-dependent setup times and machine availability constraints," Computers and Industrial Engineering, vol. 57, no. 3, pp. 949-957, 2009.

[21] W. Besbes, J. Teghem, and T. Loukil, "Scheduling hybrid flow shop problem with non-fixed availability constraints," European Journal of Industrial Engineering, vol. 4, no. 4, pp. 413-433, 2010.

[22] Y. Ma, C. Chu, and C. Zuo, "A survey of scheduling with deterministic machine availability constraints," Computers and Industrial Engineering, vol. 58, no. 2, pp. 199-211, 2010.

[23] H. Luo, G. Q. Huang, Y. Feng Zhang, and Q. Yun Dai, "Hybrid flowshop scheduling with batch-discrete processors and machine maintenance in time windows," International Journal of Production Research, vol. 49, no. 6, pp. 1575-1603, 2011. 
[24] E. Safari and S. J. Sadjadi, "A hybrid method for flowshops scheduling with condition-based maintenance constraint and machines breakdown," Expert Systems with Applications, vol. 38, no. 3, pp. 2020-2029, 2011.

[25] S. Wang and M. Liu, "Two-stage hybrid flow shop scheduling with preventive maintenance using multi-objective tabu search method," International Journal of Production Research, vol. 52, no. 5, 2014.

[26] M. Rabiee, R. S. Rad, M. Mazinani, and R. Shafaei, "An intelligent hybrid meta-heuristic for solving a case of no-wait two-stage flexible flow shop scheduling problem with unrelated parallel machines," The International Journal of Advanced Manufacturing Technology, vol. 71, no. 5-8, pp. 1229-1245, 2014.

[27] H. Allaoui and A. Artiba, "Hybrid flow shop scheduling with availability constraints," in Essays in Production, Project Planning and Scheduling, pp. 277-299, Springer, 2014.

[28] T. Stützle, "Iterated local search for the quadratic assignment problem," European Journal of Operational Research, vol. 174, no. 3, pp. 1519-1539, 2006.

[29] H. Hashimoto, M. Yagiura, and T. Ibaraki, "An iterated local search algorithm for the time-dependent vehicle routing problem with time windows," Discrete Optimization, vol. 5, no. 2, pp. 434-456, 2008.

[30] P. Vansteenwegen, W. Souffriau, G. Vanden Berghe, and D. van Oudheusden, "Iterated local search for the team orienteering problem with time windows," Computers and Operations Research, vol. 36, no. 12, pp. 3281-3290, 2009.

[31] X. Dong, H. Huang, and P. Chen, "An iterated local search algorithm for the permutation flowshop problem with total flowtime criterion," Computers and Operations Research, vol. 36, no. 5, pp. 1664-1669, 2009.

[32] J. Kennedy and R. Eberhart, "Particle swarm optimization," in Proceedings of the IEEE International Conference on Neural Networks, pp. 1942-1948, Piscataway, NJ, USA, December 1995.

[33] B. Liu, L. Wang, and Y.-H. Jin, "An effective hybrid PSObased algorithm for flow shop scheduling with limited buffers," Computers and Operations Research, vol. 35, no. 9, pp. 27912806, 2008.

[34] Q.-K. Pan, M. Fatih Tasgetiren, and Y.-C. Liang, "A discrete particle swarm optimization algorithm for the no-wait flowshop scheduling problem," Computers and Operations Research, vol. 35, no. 9, pp. 2807-2839, 2008.

[35] J. Q. Li and Y. X. Pan, "A hybrid discrete particle swarm optimization algorithm for solving fuzzy job shop scheduling problem," The International Journal of Advanced Manufacturing Technology, vol. 66, no. 1-4, pp. 583-593, 2013.

[36] C. L. Chen, S. Y. Huang, Y. R. Tzeng, and C. L. Chen, "A revised discrete particle swarm optimization algorithm for permutation flow-shop scheduling problem," Soft Computing.

[37] Y. Marinakis and M. Marinaki, "Particle swarm optimization with expanding neighborhood topology for the permutation flowshop scheduling problem," Soft Computing, vol. 17, no. 7, pp. 1159-1173, 2013.

[38] P. Damodaran, A. G. Rao, and S. Mestry, "Particle swarm optimization for scheduling batch processing machines in a permutation flowshop," International Journal of Advanced Manufacturing Technology, vol. 64, no. 5-8, pp. 989-1000, 2013.

[39] G. Vijay chakaravarthy, S. Marimuthu, and A. Naveen Sait, "Performance evaluation of proposed differential evolution and particle swarm optimization algorithms for scheduling $\mathrm{m}$ machine flow shops with lot streaming," Journal of Intelligent Manufacturing, vol. 24, no. 1, pp. 175-191, 2013.
[40] Y. Y. Chen, C. Y. Cheng, L. C. Wang, and T. L. Chen, "A hybrid approach based on the variable neighborhood search and particle swarm optimization for parallel machine scheduling problems: a case study for solar cell industry," International Journal of Production Economics, vol. 141, no. 1, pp. 66-78, 2013.

[41] S. A. Torabi, N. Sahebjamnia, S. A. Mansouri, and M. A. Bajestani, "A particle swarm optimization for a fuzzy multi-objective unrelated parallel machines scheduling problem," Applied Soft Computing, vol. 13, no. 12, pp. 4750-4762, 2013.

[42] J. Q. Li and Y. X. Pan, "A hybrid discrete particle swarm optimization algorithm for solving fuzzy job shop scheduling problem," The International Journal of Advanced Manufacturing Technology, vol. 66, no. 1-4, pp. 583-596, 20132013.

[43] J. T. Tsai, C. I. Yang, and J. H. Chou, "Hybrid sliding level Taguchi-based particle swarm optimization for flowshop scheduling problems," Applied Soft Computing, vol. 15, pp. 177-192, 2014.

[44] M. Nawaz, E. E. Enscore Jr., and I. Ham, "A heuristic algorithm for the m-machine, n-job flow-shop sequencing problem," Omega, vol. 11, no. 1, pp. 91-95, 1983.

[45] R. Ruiz, C. Maroto, and J. Alcaraz, "Two new robust genetic algorithms for the flowshop scheduling problem," Omega, vol. 34, no. 5, pp. 461-476, 2006.

[46] J. Carlier and E. Néron, "An exact method for solving the MultiProcessor Flow-Shop," Operations Research, vol. 34, no. 1, pp. 125, 2000.

[47] R. Ruiz and C. Maroto, "A genetic algorithm for hybrid flowshops with sequence dependent setup times and machine eligibility," European Journal of Operational Research, vol. 169, no. 3, pp. 781-800, 2006.

[48] R. Ruiz and T. Stützle, "A simple and effective iterated greedy algorithm for the permutation flowshop scheduling problem," European Journal of Operational Research, vol. 177, no. 3, pp. 2033-2049, 2007.

[49] C.-J. Liao, C.-T. T. Tseng, and P. Luarn, "A discrete version of particle swarm optimization for flowshop scheduling problems," Computers and Operations Research, vol. 34, no. 10, pp. 3099-3111, 2007.

[50] J.-Q. Li, Q.-K. Pan, and Y.-C. Liang, "An effective hybrid tabu search algorithm for multi-objective flexible job-shop scheduling problems," Computers and Industrial Engineering, vol. 59, no. 4, pp. 647-662, 2010.

[51] J.-Q. Li, Q.-K. Pan, and K.-Z. Gao, "Pareto-based discrete artificial bee colony algorithm for multi-objective flexible job shop scheduling problems," International Journal of Advanced Manufacturing Technology, vol. 55, no. 9-12, pp. 1159-1169, 2011.

[52] J.-Q. Li, Q.-K. Pan, P. N. Suganthan, and T. J. Chua, "A hybrid tabu search algorithm with an efficient neighborhood structure for the flexible job shop scheduling problem," International Journal of Advanced Manufacturing Technology, vol. 52, no. 58, pp. 683-697, 2011. 

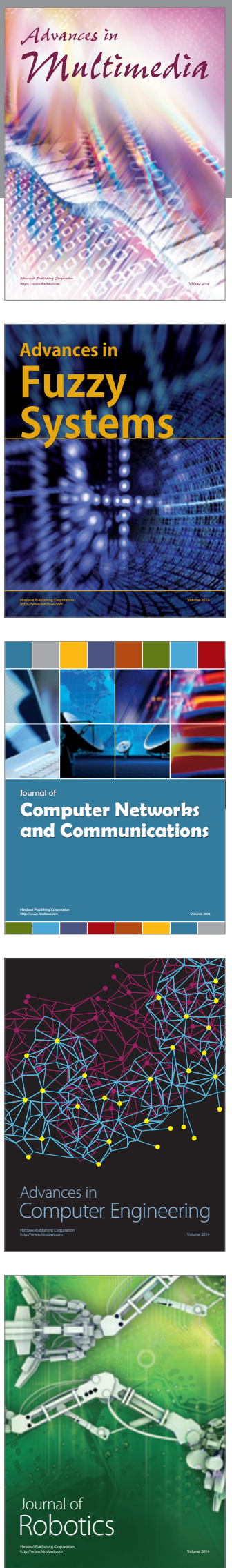

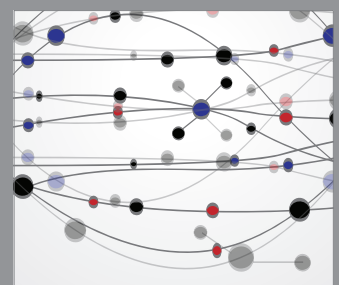

The Scientific World Journal
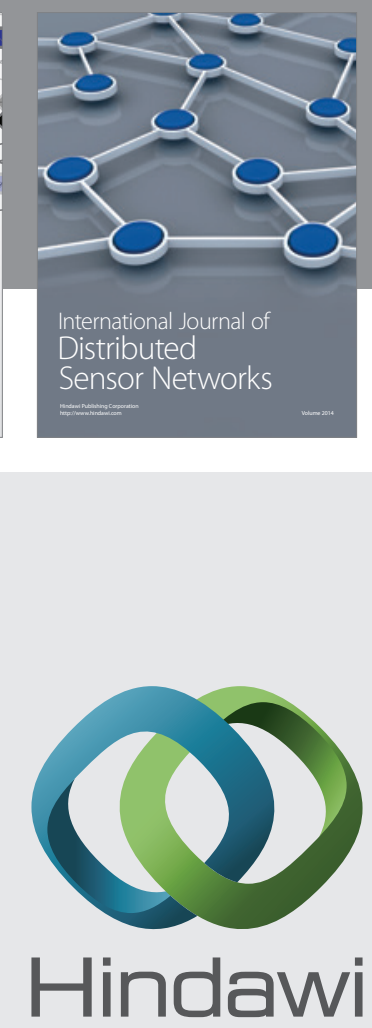

Submit your manuscripts at

http://www.hindawi.com
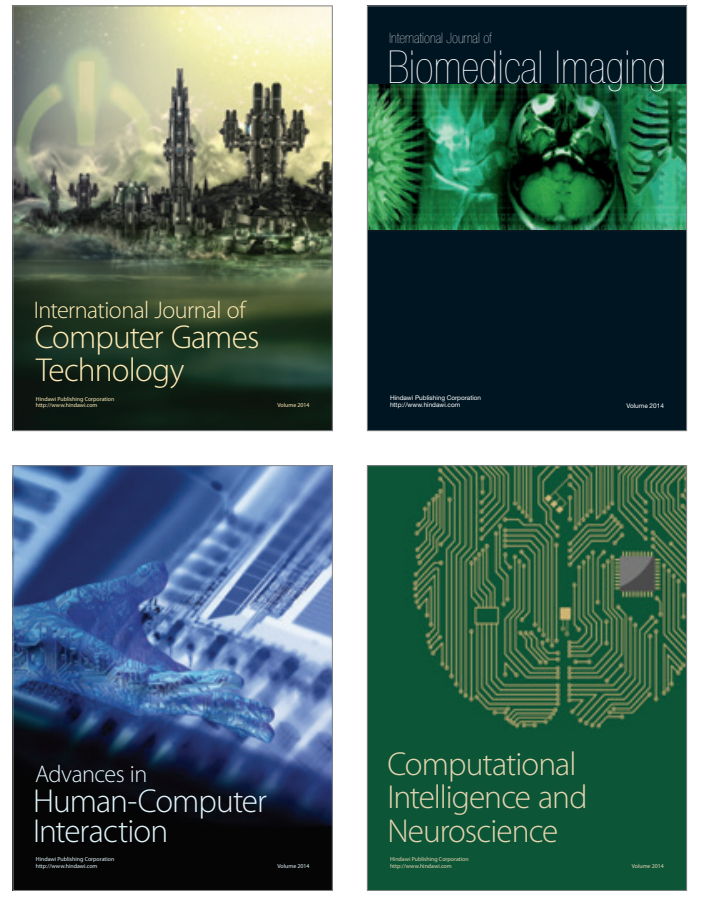
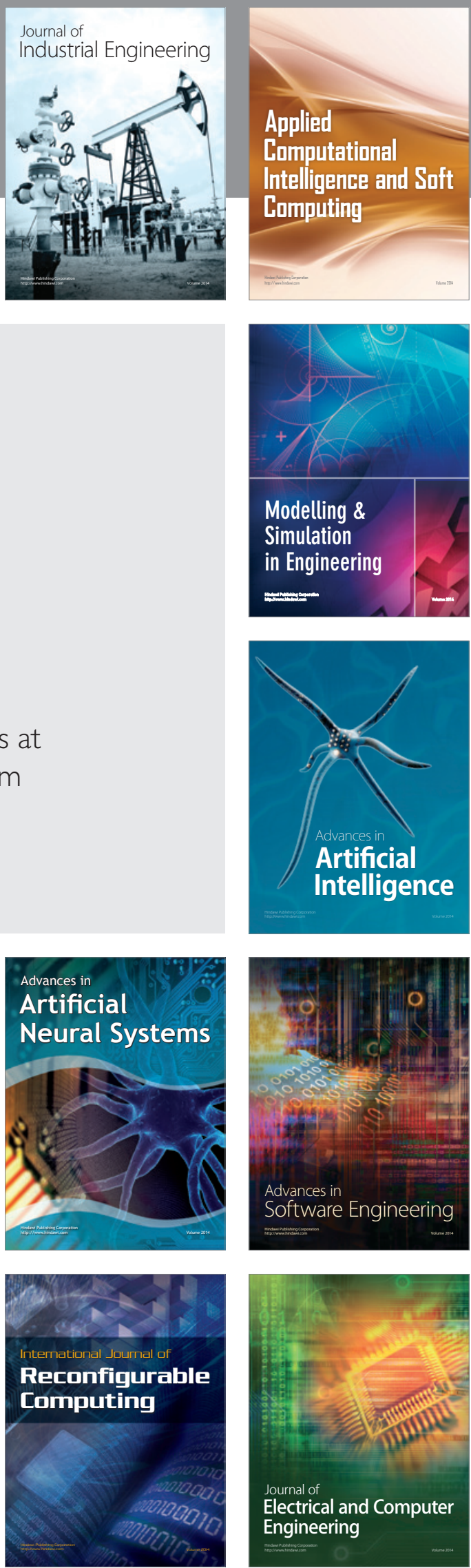